\title{
Do texto ao contexto: o Programa Ensino Médio Inovador em movimento
}

\author{
Monica Ribeiro da Silva a \\ Vanessa Campos de Lara Jakimiu ${ }^{\text {b }}$
}

\section{Resumo}

O objetivo do artigo é analisar uma política educacional a partir da produção de seus textos de referência. Utiliza-se para esse fim a elaboração teórica de S. Ball em torno da Abordagem do Ciclo de Políticas. Toma-se uma política educacional recente, o Programa Ensino Médio Inovador (ProEMI), haja vista o conjunto de documentos produzidos em curto espaço de tempo, bem como as intenções do Programa de induzir a mudanças na organização curricular das escolas de Ensino Médio. A análise sinaliza para a hipótese de que as alterações nos documentos são, ao menos em parte, resultantes de um processo de acomodação entre o que é prescrito pelo órgão de governo e as condições de realização do Programa, bem como pela amplitude do universo de interlocutores envolvidos.

Palavras-chave: Política educacional. Ensino médio. Programa ensino médio inovador. Abordagem do ciclo de políticas.

\section{Introdução}

O Ensino Médio tem vivenciado uma série de fragilidades, apresentando desafios estruturais, de recursos humanos e organizativos. Além do constante debate em torno da identidade desta etapa da Educação Básica, a questão acerca do sentido da escola para os jovens, a ausência de professores formados nas especialidades do currículo, a questão do financiamento, os problemáticos índices de desempenho expressos em avaliações, as deficiências estruturais dos prédios escolares, e os embates em torno da necessária superação de um currículo que historicamente é constituído pela fragmentação e hierarquização entre as disciplinas apresentam-se como grandes desafios a serem superados.

\footnotetext{
a Universidade Federal do Paraná - UFPR, Programa de Pós-graduação em Educação. Curitiba, Paraná, Brasil.

b Universidade Estadual do Paraná - UNESPAR. União da Vitória, Paraná, Brasil.
} 
Com o objetivo anunciado de assegurar o acesso à educação de qualidade aos jovens do Ensino Médio e enfrentar o quadro brevemente exposto, o Ministério da Educação (MEC) vem ampliando suas ações nas duas últimas décadas ${ }^{1}$ por meio de políticas e programas educacionais que trazem em seus enunciados a intenção de atender de maneira mais efetiva a este público (BRASIL, 2013a). Dentre estas ações, destaca-se o Programa Ensino Médio Inovador (ProEMI).

O ProEMI teve início no ano de 2009, instituído pela Portaria Ministerial ${ }^{\circ}$ 971, de 09 de outubro (BRASIL, 2009a). É uma ação do Ministério da Educação e para ser implementado conta com a adesão das redes e escolas estaduais. Gradativamente o ProEMI ampliou seu campo de ação e a cada ano é facultada nova oportunidade de adesão. Em seu início, em caráter experimental, foram contempladas $355^{2}$ unidades escolares em 18 Estados $^{3}$. (ASCOM SEDUC, 2012; GARCIA, 2013; KRAWCZYK, 2013). No ano de 2014, eram 5,6 mil escolas a fazerem a adesão (LORENZONI, 2014), dado este que revela ampla aceitação por parte das escolas e que pode ser um indicativo da histórica demanda por políticas educacionais para o Ensino Médio, uma vez que:

no contexto histórico da educação brasileira, [...] o ensino fundamental e a educação superior tiveram seus objetivos e finalidades melhor delineados nas legislações educacionais, sendo que, só a partir da aprovação da Lei de Diretrizes e Bases da Educação Nacional, em 1996, o ensino médio passou a ser visto como etapa da educação básica, com diretrizes e finalidades expressas nos Artigos 35 e 36 da referida Lei (BRASIL, 2009a, p. 4).

\footnotetext{
Pode-se mencionar o Programa de Melhoria e Expansão do Ensino Médio (PROMED), o Projeto Alvorada, a criação do Fundo de Manutenção e Desenvolvimento da Educação Básica e de Valorização dos Profissionais da Educação (FUNDEB), o Programa Escola Aberta (PEA), o Programa Dinheiro Direto na Escola (PDDE), o Programa de Equalização das Oportunidades de Acesso à Educação Básica (PRODEB), o Plano de Ações Articuladas (PAR), o Plano Nacional do Livro Didático (PNLD), o Plano Nacional da Biblioteca Escolar (PNBE), o Programa Nacional de Transporte Escolar (PNTE), o Programa de Alimentação Escolar (PNAE), o Plano de Desenvolvimento da Educação (PDE), entre outros.

2 Sobre este dado cabe salientar que parece não haver consenso quanto ao número de escolas contempladas pelo ProEMI no ano de 2009. As autoras supracitadas falam em 355 escolas. Em documento não publicado e concedido pelo MEC para fins da pesquisa, foi encontrado o registro de 354 escolas (BRASIL. Ministério da Educação. Secretaria de Educação Básica. Diretoria de Concepções e Orientações Curriculares para a Educação Básica. Coordenação Geral de Ensino Médio. Programa ensino médio inovador: lista das escolas a serem contempladas pelo Programa Dinheiro Direto na Escola - exercício 2010. Documento de circulação restrita ao MEC disponibilizado em: 01 mar). Já Melo e Duarte (2011) - sem mencionar fonte - falam em 357 escolas. (MELO; DUARTE, 2011, p.236).

3 No ano de sua criação, 17 Estados e o Distrito Federal fizeram a adesão ao ProEMI, totalizando, assim, 66,67\% de participação dos entes federados. Foram as unidades federativas que não aderiram ao Programa, em 2009: Alagoas, Ceará, Espírito Santo, Minas Gerais, Rio Grande do Sul, Rondônia, Roraima, São Paulo e Tocantins. Em janeiro de 2014 as 27 unidades da Federação haviam feito adesão ao Programa. (BRASIL, 2014).
} 
De acordo com Hofling (2001), as políticas públicas caracterizam o Estado em ação. Seria, pois, "o Estado implantando um projeto de governo, através de programas, de ações voltadas para setores específicos da sociedade" (HOFLING, 2001, p. 31). De modo geral, uma política pública é criada para atender à demanda de uma determinada realidade, ou seja, a gênese da criação das políticas são os tensionamentos advindos dos diferentes segmentos a partir das condições objetivas em que estes encontram-se imersos: "O processo de definição de políticas públicas para uma sociedade reflete os conflitos de interesses, os arranjos feitos nas esferas de poder que perpassam as instituições do Estado e da sociedade como um todo" (HOFLING, 2001, p. 38).

Políticas públicas são compreendidas neste estudo como um ramo da ciência política que busca compreender os movimentos que visam a "colocar o governo em ação e/ou analisar essa ação [...] e, quando necessário, propor mudanças no rumo ou curso dessas ações", focalizando, portanto, "as explicações sobre a natureza da política pública e seus processos" (SOUZA, 2006, p. 6-7).

No caso da educação brasileira, o quadro situacional que revela as demandas educacionais é retratado pelos dados de acesso, permanência e conclusão como também pelos resultados expressos nos índices obtidos por meio das avaliações ${ }^{4}$, informações estas que tornam públicas as fragilidades da realidade educacional. Neste contexto, as políticas educacionais são apresentadas tanto como uma resposta do Estado para alterar a realidade apresentada por meio destes indicadores visando superar tais fragilidades, quanto como uma resposta às demandas suscitadas pela sociedade civil e política.

Tendo em vista que, desde a sua criação, o Programa Ensino Médio Inovador, objeto de nosso estudo, passou por várias reformulações, tanto em seus pressupostos teóricos quanto em suas orientações didático-metodológicas, no presente texto ${ }^{5}$, nos propomos a mostrar o movimento do ProEMI, considerando-o parte de uma política educacional que visa a induzir a mudanças na organização pedagógica das escolas, notadamente nos modos de conceber e tratar os sujeitos, os tempos, os espaços e o conhecimento escolar. Para esse fim, tomamos como pressuposto e referencial de análise as formulações de Stephen Ball no que diz respeito à Abordagem do Ciclo de Políticas. Assim, a primeira seção do artigo busca

\footnotetext{
4 Dentre esses dados estão os obtidos na composição do Índice de Desenvolvimento da Educação Básica (IDEB), no Sistema de Avaliação da Educação Básica (SAEB) e no Exame Nacional do Ensino Médio (ENEM).

5 O artigo resulta de pesquisa que teve por objetivo analisar os processos de implementação do ProEMI entre os anos de 2009 e 2014. Um dos eixos investigativos tratou do estudo documental, resultados ora apresentados. A pesquisa contou com financiamento CAPES e CNPq.
} 
explicitar no que, em nosso entendimento, essa abordagem pode contribuir para o estudo em tela. Em seguida, trazemos a análise das proposições dos Documentos Orientadores com vistas à implementação do ProEMI em suas várias versões (BRASIL, 2009b e 2009c, 2011a, 2013a e 2013b).

Com base nos estudos preliminares e no referencial teórico citado, definimos como hipótese orientadora da pesquisa documental que as alterações nos textos de referência do ProEMI são, ao menos em parte, resultantes de um processo de acomodação entre o que é prescrito pelo órgão de governo e as condições de realização do Programa pelas redes de ensino e escolas, e/ou ainda por possíveis mudanças nos interlocutores ao longo dos cinco anos de existência do Programa.

Nas considerações finais, tecemos uma breve síntese dos achados da pesquisa bem como destacamos a potencialidade da Abordagem do Ciclo de Políticas, haja vista que este referencial permitiu identificar um movimento entre texto e contexto, a partir do qual se constata que as alterações nos textos de referência do ProEMI resultaram de um conjunto de influências advindas dos formuladores de outros instrumentos normativos, de outras ações da política educacional para o Ensino Médio, da interlocução direta com os sujeitos nas escolas, bem como pelas condições de exequibilidade das induções feitas pelo Programa.

\section{Stephen Ball e a abordagem do ciclo de políticas}

A Abordagem do Ciclo de Políticas (ACP) ou Policy Cycle Approach, elaborada por Stephen Ball e colaboradores (MAINARDES, 2006), refere-se a uma perspectiva de análise de políticas. Ball (1994) já sinaliza que não há coincidência entre os processos pelos quais as políticas são elaboradas e os procedimentos com os quais são analisadas (BALL, 1994; MAINARDES; MARCONDES, 2009). E, ainda, a ACP se configura como uma estrutura conceitual e metodológica que oferece possibilidades de análise da trajetória de políticas (LOPES; MACEDO, 2011).

Inicialmente pensada a partir de três contextos ${ }^{6}-$ Contexto de Influência, Contexto da Produção de texto e Contexto da Prática - aos quais se agregaram posteriormente o Contexto de Efeito ou Resultados e o Contexto da Estratégia, a ACP oferece possibilidades de interpretação acerca das trajetórias de políticas que ultrapassam o esquadrinhamento em fases desarticuladas e estanques, que, quando utilizado, ao nosso ver se configuram em perspectivas limitadoras e simplificadoras da análise.

A trajetória de constituição da Abordagem do Ciclo de Políticas encontra-se desenvolvida por Mainardes (2006) com base nos escritos de Ball e Bowe (1992) e Ball. (1994). 
Desse modo, entendemos que a Abordagem do Ciclo de Políticas não comporta o fatiamento em fases, como se cada um dos contextos arrolados existisse de forma independente do outro. Ao contrário, essa perspectiva analítica permite notar que há um entrelaçamento do qual resulta um complexo enredo que marca as estruturas discursivas e a composição textual e contextual no qual a política se move, sem caracterizarem linearidades ou dimensões temporais (MAINARDES, 2006).

O contexto de influência é marcadamente o momento em que as lutas pela produção de hegemonias se vão instituindo (LOPES; MACEDO, 2011). No entanto, esse processo de hegemonização ou de luta pelos significados se impõe em todos os momentos da trajetória de uma política. Isso evidencia o entrelaçamento entre os vários contextos ao qual nos referimos anteriormente.

No contexto de influência se observa a presença dos mais variados atores e das ideias que veiculam - dos partidos políticos aos sujeitos diretamente envolvidos com a formulação e execução das políticas - nele se observam as tensões e acordos a partir dos quais se configura o contexto da produção do texto (BALL, 1994; MAINARDES, 2006; LOPES; MACEDO, 2011). Os movimentos desencadeados e captados nesses contextos embasam a análise na direção do que é praticado (contexto da prática), bem como dos prováveis efeitos e estratégias derivadas das induções feitas. Esses contextos, partilhados e contrastantes, representam arenas, lugares e interesses a partir dos quais a política ganha forma e pode ser compreendida.

Nesse intrincado processo analítico, Ball (1994) salienta que os efeitos de uma política são de duas ordens: os efeitos de primeira ordem, que traduzem as "mudanças na prática ou na estrutura e são evidentes em lugares específicos ou no sistema como um todo" (BALL apud MAINARDES, 2006, p. 55); e os efeitos de segunda ordem, que se referem "ao impacto dessas mudanças nos padrões de acesso social, oportunidade e justiça social” (BALL apud MAINARDES, 2006, p. 55). Ball (1994) assevera, por outro lado, que a ACP permite, para além de identificar esses efeitos, adentrar os lugares de disputa e, com isso, captar os sentidos e os significados conferidos nos diferentes contextos a partir dos quais a política se movimenta.

No presente texto, assumimos como pressuposto que a ACP se institui potencialmente como referencial teórico-analítico, tendo em vista o objeto que pretendemos analisar, qual seja, o movimento do Programa Ensino Médio Inovador considerando como base para o estudo os textos de referência produzidos com vistas a orientar sua implementação. 


\section{O ProEMI em movimento: as versões dos Documentos Orientadores}

\subsection{O Documento Orientador do Programa Ensino Médio Inovador - 2009}

O ProEMI foi criado para provocar o debate sobre o Ensino Médio junto aos Sistemas de Ensino Estaduais e Distrital e induzir o fomento de propostas curriculares inovadoras, as quais ao pretender implementar um "currículo dinâmico, flexível e que atenda às demandas da sociedade contemporânea" (BRASIL, 2013b, p. 10), buscam enfrentar as características que marcam o currículo do Ensino Médio ao longo da história, principalmente a fragmentação e hierarquização dos saberes presentes em um currículo marcado por uma lógica estritamente disciplinar.

Em vista disso, em abril de 2009, é disponibilizada uma versão preliminar do documento orientador que o apresenta como um Programa de apoio para promover inovações pedagógicas nas escolas públicas em nível médio, as quais seriam consolidadas a partir de mudanças na organização curricular bem como a partir do reconhecimento da singularidade dos sujeitos que se encontram nas escolas em todo o Brasil (BRASIL, 2009b).

O documento orientador de abril de 2009 apresenta um quadro situacional do Ensino Médio no Brasil e apresenta o aporte conceitual que delineia os pressupostos do Programa. Enquanto pressupostos para a organização de um currículo inovador no Ensino Médio, o Programa apresenta proposições que pressupõem uma perspectiva de articulação interdisciplinar, voltada para o desenvolvimento de conhecimentos - saberes, competências, valores e práticas (BRASIL, 2009b). O documento faz, ainda, menção a novas formas de organização das disciplinas articuladas com atividades integradoras, a partir das inter-relações entre trabalho, ciência, tecnologia e a cultura.

Nesse primeiro movimento, identificamos duas vertentes no contexto de influência da composição do discurso curricular que embasa o ProEMI: a primeira, caudatária das políticas curriculares que o antecederam, notadamente do Parecer CNE/CEB $\mathrm{n}^{\circ}$ 15/98 (BRASIL, 1998) que estabeleceu as Diretrizes Curriculares Nacionais para o Ensino Médio e se firmavam em torno do conceito de "competências"; e, o segundo, emanado das primeiras mudanças de direção quando assume o governo do Partido dos Trabalhadores, cujo projeto formativo é enunciado em torno do eixo "ciência, cultura e trabalho". Para essa última perspectiva, tais elementos seriam desenvolvidos de forma integrada aos diversos conhecimentos 
e estariam alicerçados em uma base unitária "sobre a qual podem se assentar possibilidades diversas de formações específicas: no trabalho, como formação profissional; na ciência, como iniciação científica; na cultura, como ampliação da formação cultural" (BRASIL, 2009b).

Na versão preliminar do documento orientador, o Projeto Político Pedagógico (PPP) adquire centralidade para a materialização da articulação entre trabalho, ciência, tecnologia e cultura, ou seja, a mudança curricular se tornaria permanente e institucionalizada na organização e rotina escolar. A ênfase no PPP buscava garantir uma proposta consistente de organização curricular nos planos de ensino, nos planos de aula, bem como na prática educativa dos educadores. Esta (re) organização do PPP, deveria ser realizada visando:

- Contemplar atividades integradoras [...]; - Incorporar, como princípio educativo, a metodologia da problematização como instrumento de incentivo a pesquisa [...]; - Promover a aprendizagem criativa [...]; - Promover a valorização da leitura em todos os campos do saber, [...]; Fomentar o comportamento ético, como ponto de partida para o reconhecimento dos deveres e direitos da cidadania; [...]; - Articular teoria e prática [...]; - Utilizar novas mídias e tecnologias educacionais, [...]; - Estimular a capacidade de aprender do aluno [...]; - Promover atividades sociais que estimulem o convívio humano e interativo do mundo dos jovens; - Promover a integração com o mundo do trabalho por meio de estágios direcionados para os estudantes do ensino médio; - Organizar os tempos e espaços com ações efetivas de interdisciplinaridade e contextualização dos conhecimentos; - Garantir o acompanhamento da vida escolar dos estudantes [...]; - Ofertar atividades complementares e de reforço da aprendizagem [...]; - Ofertar atividades de estudo com utilização de novas tecnologias de comunicação; e, - Avaliação da aprendizagem como processo formativo e permanente de reconhecimento de saberes, competências, habilidades e atitudes (BRASIL, 2009b, p. 17-18).

Além da ampliação do tempo ${ }^{7}$ e das atividades integradoras, as demandas e perspectivas dos jovens também deveriam ser consideradas e se expressariam na intenção de induzir a organização de um currículo capaz de "promover uma aprendizagem que faça sentido para os jovens adolescentes" (BRASIL, 2009b,

\footnotetext{
7 Um dos fatores relacionados ao percurso formativo do novo currículo proposto pelo ProEMl está relacionado com a ampliação do tempo de permanência do estudante na escola. Atualmente, temos como deliberação da LDBEN, a carga horária mínima de 800 horas anuais, distribuídas em 200 dias letivos. (BRASIL, 1996). A partir da adesão ao ProEMl, a ideia é aumentar a carga horária anual para no mínimo 3 mil horas ao longo dos três anos.
} 
p. 5). Segundo o documento orientador (2009a), tais proposições estão sujeitas ao processo de adequação e legitimação nos espaços escolares ${ }^{8}$ (BRASIL, 2009b).

Segundo preconiza ainda a primeira versão do documento orientador (BRASIL, 2009b), a organização curricular do Ensino Médio deveria: a) Considerar as diretrizes curriculares nacionais, b) Respaldar-se nos fundamentos das teorias educacionais, e c) Possibilitar a participação coletiva dos sujeitos envolvidos.

Na perspectiva defendida pelo ProEMI, "ninguém mais do que a própria comunidade escolar, o coletivo, conhece a sua realidade e, portanto, está mais habilitado para tomar decisões a respeito do currículo que vai, efetivamente, ser praticado" (BRASIL, 2009b, p. 18). Assim, os projetos das escolas contendo as propostas de experiências de inovação curricular, conforme as diretrizes gerais do Programa, deveriam ser registradas no Plano de Ação Pedagógica (PAP) e enviadas à Secretaria Estadual de Educação que, por sua vez, o encaminharia à Secretaria de Educação Básica do MEC. O PAP era considerado como o:

documento suporte para a análise do Comitê Técnico, podendo ser diligenciado, quando da necessidade de ajustes e complementações, constituindo-se como instrumento base para a elaboração dos respectivos planos de trabalhos que fundamentarão os convênios a serem firmados, como procedimento para o apoio financeiro pretendido (BRASIL, 2009b, p. 20).

Embora em 2009, o Programa já previsse apoio financeiro, o documento orientador não apresentava especificação quanto aos critérios de repasse e/ou encaminhamentos normativos para a destinação de tais recursos (BRASIL, 2009b).

A avaliação e monitoramento do Programa ficaria a cargo da Diretoria de Concepções e Orientações Curriculares para a Educação Básica recebendo, também, apoio do INEP e de instituições universitárias por "meio da operação e manutenção de sistema informatizado de registro e processamento de dados, especialmente os referentes aos indicadores educacionais do Sistema Nacional de Avaliação" (BRASIL, 2009b, p. 27).

\footnotetext{
Para além do aporte conceitual, percebe-se uma intenção do Programa em garantir as condições mínimas de qualidade que permitam colocar em prática as intenções de mudanças necessárias em termos de currículo nas escolas de Ensino Médio. Para tal, o Programa propõe linhas de ação que envolvem aspectos que permeiam o contexto escolar, e, portanto, forneceriam subsídios para a implementação do ProEMI, sendo eles: a) Fortalecimento da Gestão Estadual de Ensino Médio; b) Fortalecimento da Gestão das Unidades Escolares; c) Melhoria das Condições de Trabalho Docente e Formação Continuada; d) Apoio às Práticas Docentes; e) Desenvolvimento do Protagonismo Juvenil e Apoio ao Aluno Jovem e Adulto Trabalhador; f) Infraestrutura física e Recursos Pedagógicos; e g) Pesquisas e Estudos do Ensino Médio e juventude (BRASIL, 2009b).
} 
Já de início, houve duas versões do documento orientador do ProEMI. Isso porque as proposições da primeira versão sofreram modificações após análise do Conselho Nacional de Educação consubstanciada no Parecer CNE/CP n ${ }^{\circ}$ 11/2009 (BRASIL, 2009d).

Em fevereiro de 2009, por meio do Ofício MEC n ${ }^{\circ} 18$, o Ministro da Educação encaminhou ao Conselho Nacional de Educação (CNE) um documento que apresentava uma proposta de experiência curricular que induziria à inovação no Ensino Médio solicitando sua apreciação, "em regime de urgência, como programa experimental, nos termos do artigo 81 da Lei no 9394/96 (LDB)" (BRASIL, 2009a, p. 1).

Como resposta ao MEC, o CNE emitiu o Parecer CNE/CP n ${ }^{\circ}$ 11/2009 (BRASIL, 2009d). As mudanças mais significativas, do ponto de vista da organização curricular, apontadas no Parecer e que foram incorporadas na versão oficial do ProEMI, publicado em setembro de 2009, foram a inclusão de novos itens a serem considerados para a elaboração do Projeto Político Pedagógico e a inclusão e alteração de ações para orientar a elaboração dos Projetos Escolares. O Parecer do CNE referendou, ainda, a natureza experimental do Programa e indicou que o mesmo fosse executado por meio do regime de colaboração entre a União e as unidades da federação. Aqui já se evidencia o cenário marcado por aquilo que, conforme Ball (1994), denominamos contexto de influência. A ação dos interlocutores privilegiados instados nesse contexto incide diretamente sobre a produção do texto de referência bem como dos rumos iniciais da política.

Para a elaboração dos Projetos Escolares, o documento que serve de base para a implementação do ProEMI (BRASIL, 2009c) incorpora os itens dispostos no documento orientador de abril (BRASI, 2009b) e acrescenta, por sugestão do Conselho Nacional de Educação:

- Reconhecer as diferentes facetas da exclusão na sociedade brasileira, para assegurar a ampliação do acesso aos sujeitos historicamente excluídos do Ensino Médio; - Garantir a inclusão das temáticas que valorizem os direitos humanos e contribuam para o enfrentamento do preconceito, da discriminação e da violência no interior das escolas; - Desenvolver a compreensão da realidade brasileira, de sua organização social e produtiva na relação de complementaridade entre espaços urbanos e rurais; Valorizar o estudo e as atividades socioambientais e projetos de extensão; - Desenvolver conhecimentos e habilidades associados a 
aspectos comportamentais (relacionamento, comunicação, iniciativa, cooperação, compromisso), relativos às atividades de gestão e de iniciativas empreendedoras; - Valorizar práticas desportivas e de expressão corporal, referidas à saúde, à sociabilidade e à cooperação; e - Estimular a participação social dos jovens, como agentes de transformação de suas escolas e de suas comunidades (BRASIL, 2009c, p.10).

Quanto às ações para orientar a elaboração dos Projetos Escolares, a versão de setembro de 2009 mantém a indicação de ampliação da carga horária para no mínimo 3.000 horas, no entanto, possibilita que esta ampliação se inicie com 2.400 horas obrigatórias, acrescidas de mais 600 horas a serem implantadas de forma gradativa. (BRASIL, 2009c). A mudança, derivada igualmente da interlocução com o CNE, provavelmente leva em consideração as condições de exequibilidade do pretendido aumento da jornada escolar.

A destinação de $20 \%$ da carga horária para estudos e atividade de interesse do aluno, por meio de atividades optativas e disciplinas eletivas, foi considerada pelo Parecer CNE/CP n ${ }^{\circ}$ 11/2009 "estratégia adequada para propiciar, em um mesmo curso, a construção de percursos e itinerários formativos que atendam à diversidade de interesses, anseios, condições e projetos de vida dos jovens alunos" (BRASIL, 2009d, p. 17), no entanto, reconhecendo os limites de algumas escolas, especialmente das de pequeno porte em ofertar atividades optativas e disciplinas eletivas, a Comissão Especial, responsável pela redação do Parecer $\mathrm{CNE} / \mathrm{CP} n^{\circ} 11 / 2009$ sugere que sejam firmadas parcerias com outras instituições escolares com vistas a:

Incentivar a cooperação e intercomplementaridade entre escolas, para que constituam "comunidades interescolares", sobretudo para possibilitar aos alunos um maior leque de opções para acolher a diversidade de interesses que surgirem para os componentes flexíveis e variáveis que integrem o mínimo de $20 \%$ de atividades optativas (BRASIL, 2009d, p.21 - grifo do autor).

Observa-se que a versão do documento orientador de setembro de 2009 (BRASIL, 2009c) deixa de estabelecer uma determinada porcentagem da carga horária total do curso para as atividades optativas, prevendo que estas possam "estar estruturadas em disciplinas, se assim vierem a se constituir, eletivas pelos estudantes, sistematizadas e articuladas com os componentes curriculares obrigatórios" (BRASIL, 2009c, p. 11). 
O documento orientador de setembro de 2009, diferentemente da versão anterior, prevê que a organização curricular se apresente articulada aos exames do Sistema Nacional de Avaliação da Educação Básica (SAEB) e às matrizes de referência do novo ENEM (BRASIL, 2009c). Além disso, o Instituto Nacional de Estudos e Pesquisas Educacionais Anísio Teixeira (INEP) passaria a coordenar a avaliação externa do Programa Ensino Médio Inovador.

Do processo inicial da composição do discurso que daria origem ao Programa Ensino Médio Inovador, identificamos os primeiros movimentos dos muitos que irão dar contorno à sua contextura. Nas propostas do Conselho Nacional de Educação, evidenciam-se os primeiros sinais de acomodação, que caracteriza, neste caso, o contexto de influência conforme a ACP, derivados provavelmente de embates de duas ordens: as distintas percepções dos Conselheiros sobre o que tem sido praticado no Ensino Médio e as condições mesmas das redes estaduais de ensino.

\subsection{O Documento Orientador do Programa Ensino Médio Inovador - 2011}

Em 2011, é apresentada uma nova versão do documento orientador do ProEMI e que traz alterações quanto às orientações para a organização de uma outra base curricular para o Ensino Médio.

Assim como na versão anterior (Brasil, 2009c), o documento de 2011 enfatiza os dados/indicadores do Ensino Médio, no entanto, a discussão conceitual acerca dos fundamentos teóricos que orientariam as ações do ProEMI não se faz mais presente. $\mathrm{O}$ documento deixa tais fundamentos subentendidos e esclarece que todas as ações do ProEMI devem estar em consonância com as "Diretrizes Gerais para a Educação Básica (2012), as Diretrizes Curriculares Nacionais do Ensino Médio9, [...] as matrizes de referência do novo ENEM. Considerando também, as bases legais constituídas pelos Sistemas Estaduais de Ensino" (BRASIL, 2011a, p.6).

O ProEMI, na versão de 2011, é apresentado como uma estratégia do Governo Federal no sentido de

induzir a reestruturação dos currículos do Ensino Médio, compreendendo que as ações propostas inicialmente vão sendo incorporadas ao currículo

\footnotetext{
9 Vale, no entanto, ressaltar que as Diretrizes Curriculares Nacionais para o Ensino Médio se encontravam, quando da divulgação do Documento Orientador do ProEMI em 2011, a "meio caminho", isto é, havia um Parecer aprovado pelo CNE 05/2011 (BRASIL, 2001b) mas ainda não homologado pelo Ministro da Educação, o que viria a ocorrer somente no ano seguinte, dando origem à Resolução CNE/CEB n² 2/2012 (BRASIL, 2012).
} 
das escolas, ampliando o tempo na escola e a diversidade de práticas pedagógicas, atendendo às necessidades e expectativas dos estudantes do ensino médio (BRASIL, 2011, p. 6).

O documento do ProEMI de 2011 mantém a indicação de ampliação da carga horária para no mínimo 3.000 horas, estendendo-se 2.400 horas obrigatórias acrescidas de 600 horas a serem implantadas de forma gradativa, no entanto, passa a facultar às escolas a possibilidade de escolher ampliar sua carga horária para 5 ou para 7 horas. Essa possibilidade decorre provavelmente das condições reais de ampliação da jornada, que demandariam o aumento do número ou da carga horária dos professores, bem como de uma reconfiguração do espaço e das condições materiais das escolas.

Em suas proposições, o documento orientador do ProEMI (2009c) previa a atividade docente em dedicação exclusiva a qual estaria estabelecida no termo de adesão enquanto contrapartida do Estado. No entanto, o documento não mencionava como seria o processo seletivo, tampouco as atribuições deste profissional, dando a entender que todos os professores que estivessem atuando em escolas que tivessem feito adesão ao ProEMI estariam com seus professores em regime de dedicação exclusiva.

Apesar de os relatores do Parecer CNE/CP n 11 (BRASIL, 2009d) considerarem profícua a ideia de dedicação exclusiva dos professores, os mesmos - prevendo a ineficácia desta ação do ponto de vista dos recursos humanos, uma vez que a adesão ao ProEMI previa a imediata transformação do regime -, sugeriram que houvesse a progressiva implantação desta modalidade de atuação profissional.

A atividade docente em regime de dedicação em tempo integral na mesma escola é relevante, pois é uma condição saudavelmente ambiciosa quanto às condições de trabalho dos professores, pressupondo a escolha de docentes, não só titulados, como com essa dedicação para atuação nas escolas envolvidas. É oportuno, portanto, que esse programa experimental inclua essa medida, mesmo que seja progressiva sua exigibilidade e sua implantação (BRASIL, 2009d, p. 19).

A indicação acima interferiu diretamente no início da implementação do Programa, prevalecendo, portanto, as condições reais em que se dá a docência no país, marcada por processos de precarização como jornadas triplas, e/ou várias escolas para a atuação de um mesmo professor. Mostra, mais uma vez, 
a amplitude das interlocuções e dos interlocutores na formulação dos textos de referência do Programa.

A atividade docente em dedicação exclusiva passa a ser apresentada, na versão do ProEMI de 2011, enquanto uma possibilidade por meio da figura de um único Professor Articulador, ao qual caberia a responsabilidade de "exercer as funções de coordenador local e articulador das ações de organização curricular propostas" (BRASIL, 2011, p. 10).

O documento do ProEMI (2011) prevê a necessidade de no mínimo 1 professor para exercer essa função (sendo permitido haver mais de 1 professor articulador na escola), o qual deveria ser escolhido pelos professores e estar lotado na unidade escolar exercendo a função com 40 horas semanais. Além disso, o Professor Articulador precisaria pertencer ao quadro permanente e possuir formação e perfil adequados para o desenvolvimento das seguintes atribuições:

- Desenvolver e implantar estratégias para a sistematização das ideias, ações e projetos propostos pelos professores, visando à elaboração e apresentação do Projeto de Reestruturação Curricular da escola, em consonância com o Documento Base do Programa Ensino médio Inovador (ProEMI) e do Projeto Político-Pedagógico da escola; - Promover as articulações curriculares possíveis, internas e externas ao contexto escolar, estabelecidas nos projetos/ações contemplados no Projeto de Reestruturação Curricular; - Coordenar e acompanhar a execução das ações, com foco no currículo da escola; - Estabelecer canais permanentes de articulação com a Secretaria Estadual e Distrital de Educação/Coordenação Estadual de Ensino médio e com outras instituições possibilitando: I- a gestão compartilhada; II- a ampliação dos territórios educacionais; III- dinamização dos ambientes sócio-culturais existentes na região (BRASIL, 2011, p. 12-13).

Muito provavelmente a flexibilização da orientação original quanto à dedicação exclusiva e integral dos professores à escola participante do Programa decorre de sinalizações advindas das interlocuções entre agentes do Ministério da Educação, do Conselho Nacional de Educação e das redes estaduais de ensino que indicavam antecipadamente entraves para cumprimento da proposta. $\mathrm{O}$ texto final é resultado desse contexto de embates acerca dos rumos que deveria tomar a política em construção. 
Do ponto de vista da organização curricular, a mudança mais significativa é a de que a estratégia para a implementação da "inovação", que anteriormente se consolidava por meio das "Linhas de Ação", passa a ser organizada com base na ideia de "Macrocampo" 10.

Macrocampo é definido no documento orientador do ProEMI como o "conjunto de atividades didático-pedagógicas que estão dentro de uma área de conhecimento percebida como um grande campo de ação educacional e interativa, podendo contemplar uma diversidade de ações que qualificam o currículo escolar" (BRASIL, 2011, p. 14).

O ProEMI (2011) propõe que o planejamento e execução de um currículo inovador para o Ensino Médio se concretize a partir de 8 macrocampos, sendo 2 de caráter obrigatório e os outros 6 de caráter eletivo, como verificamos na Figura 1.

A escolha ${ }^{11}$ dos macrocampos eletivos estavam a cargo da escola, que elaboraria seu projeto de reestruturação curricular a partir das demandas da realidade escolar. Assim, caberia à escola propor ações nos dois macrocampos obrigatórios e em apenas alguns macrocampos eletivos, em todos, ou em nenhum macrocampo eletivo (BRASIL, 2011).

As ações dentro de cada macrocampo deveriam ter como premissa a interação direta com o estudante. Além disso, deveriam dialogar entre si e com as disciplinas constantes do currículo, observando as orientações metodológicas previstas em cada campo de saber constituídos pelos diferentes macrocampos (BRASIL, 2011).

De 2009 para 2011, é mantida a referência ao eixo "ciência, cultura e trabalho" e acrescido a ele a "tecnologia", conforme enunciava o texto das Diretrizes Curriculares Nacionais para o Ensino Médio ainda por ser homologado. A essa formulação, outros aspectos foram incorporados, dentre eles:

\footnotetext{
${ }^{10}$ É interessante observar que algumas linhas de ação tais como a implementação do Professor Articulador, a ideia do redesenho curricular por meio dos macrocampos e a ampliação do tempo de permanência dos estudantes na escola pode ter sido uma tentativa de aproximação dos dois maiores Programas executados pela Diretoria de Currículos e Educação Integral da SEB/MEC, quais sejam: o Programa mais Educação (direcionado ao Ensino Fundamental) e o Programa Ensino Médio Inovador (direcionado para o Ensino Médio).

${ }^{11}$ Outra alteração verificada consiste na mudança do nome do instrumento para o registro das ações planejadas pela escola, que na versão de 2009 aparece como Plano de Ação Pedagógica (PAP) e na versão de a, passa a ser chamado de Projeto de Reestruturação Curricular (PRC). Além disso, no documento orientador também é citado o termo Plano de Atendimento Global (PAG), no entanto, não há uma explicação sobre o sentido do termo, inclusive dando margem para interpretar que PRC e PAG poderiam ser entendidos como sinônimos.
} 


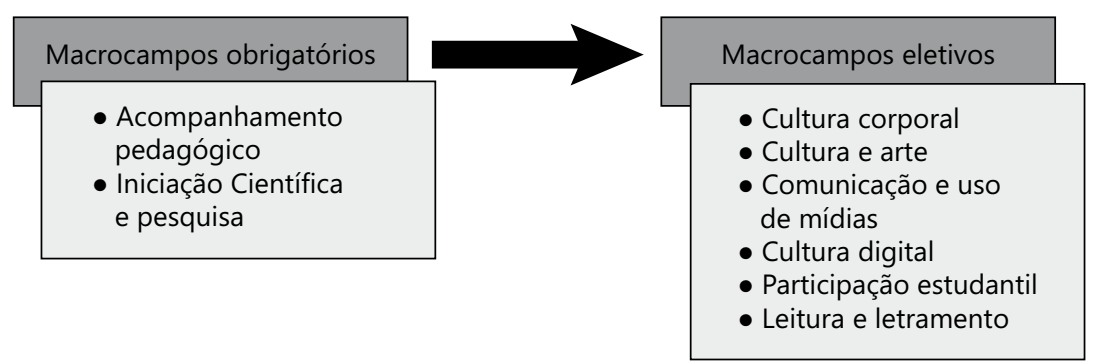

Fonte: Elaborado com base nos dados contidos no documento orientador do Programa Ensino Médio Inovador. (BRASIL, 2011).

Figura 1. Macrocampos ProEMI (2011).

e) Fomento as atividades esportivas e corporais que promovam o desenvolvimento dos estudantes; f) Fomento às atividades que envolvam comunicação e uso de mídias e cultura digital, em todas as áreas do conhecimento; g) Oferta de atividades optativas (de acordo com os macrocampos), que poderão estar estruturadas em disciplinas, ou em outras práticas pedagógicas multi ou interdisciplinares; [...] Elaboração de plano de metas para melhoria do índice escolar (BRASIL, 2011a, p. 7-8).

É importante destacar que, ainda que o documento do ProEMI na versão de 2011 tenha assumido um caráter mais propositivo quanto aos elementos para realizar a indução à mudança curricular, aspectos importantes deixaram de ser considerados, com especial destaque para as linhas de ação que traziam em seu conteúdo proposições voltadas para o fortalecimento das instituições escolares, prevendo a formação de professores e ações de cunho pedagógico que inclusive contribuiriam para o estudo dos pressupostos do ProEMI, e, em decorrência, para a implementação do Programa nas escolas.

\subsection{O Documento Orientador do Programa Ensino Médio Inovador - 2013}

O documento orientador do ProEMI de 2013 apresentou duas versões. A primeira (2013b), de caráter preliminar, foi enviada às Secretarias de Educação para que estas pudessem fazer suas observações com relação às mudanças que estavam sendo propostas. Após este trâmite é que houve a publicação da nova versão do documento orientador (BRASIL, 2013a). Vale destacar que este procedimento, bem como a elaboração dos projetos de reestruturação curricular pelas escolas, constituem um alargamento do contexto de influência na formulação dos 
documentos do Programa, e incide diretamente sobre a construção do texto de referência. Este, por sua vez, resulta, ao mesmo tempo, daquilo que tem sido praticado pelas escolas antes e depois das induções feitas pelo Programa, o que denominamos, com base em Ball (1994), por contexto da prática. Sobre esses três contextos, incidem os efeitos de primeira e de segunda ordem e as escolhas que marcam os outros dois contextos: de estratégias e de resultados.

O primeiro documento orientador do ProEMI de 2013 (BRASIL, 2013b), assim como as versões anteriores, apresenta um panorama geral do Ensino Médio, trazendo dados por meio de gráficos e tabelas, ilustrando as fragilidades e desafios desta etapa de ensino e o ProEMI passa a ser apresentado como parte integrante das ações do PDE, e continua sendo considerado como uma estratégia do Governo Federal para induzir o redesenho dos currículos em nível médio.

Assim, as proposições pedagógicas relacionadas à perspectiva de formação integral, como a busca pela consolidação de novos tempos e espaços, a ampliação do tempo de jornada escolar, bem como o planejamento de novas práticas curriculares, já propostas nos documentos anteriores, são mantidas nesta versão.

O documento orientador na versão de 2013 (BRASIL, 2013a,b) passa a utilizar a palavra redesenho curricular em substituição ao termo reestruturação curricular. Ao longo do texto, no entanto, não há nenhuma nota explicativa e/ou justificativa sobre tal mudança.

Outra mudança observada é que, na versão 2013, o documento orientador do ProEMI, além de propor que os Projetos de Redesenho Curricular sejam organizados em consonância com as Diretrizes Gerais para a Educação Básica, as Diretrizes Curriculares Nacionais do Ensino Médio e as matrizes de referência do ENEM ${ }^{12}$, também passa a sugerir que se considere as Diretrizes Curriculares Nacionais para a Educação de Jovens e Adultos e as Diretrizes Curriculares nacionais para a Educação Profissional Técnica de Nível Médio (BRASIL, 2013b), ampliando, assim, o contexto de influência que serviria de base para as redes de ensino e escolas na elaboração de seus projetos de redesenho curricular.

Nas versões do documento orientador de 2013, o conceito de macrocampo é ampliado, e é apresentado como o eixo a partir do qual se torna possível

\footnotetext{
${ }^{12}$ A partir de 2009, o ENEM passou a ser utilizado também como mecanismo de seleção para o ingresso no ensino superior. Atualmente, a seleção ocorre via Sistema de Seleção Unificada (Sisu) e via Programa Universidade para Todos (ProUni). O ENEM é válido também para o ingresso em programas como o Pronatec e o Ciência sem Fronteiras, o que fez com que o exame passasse a atuar, tangencialmente, como um indutor do currículo do Ensino Médio, paralelamente ao currículo inovador proposto pelo ProEMI.
} 
realizar a integração curricular. Assim, a partir de 2013, macrocampo passa a ser entendido como:

um campo de ação pedagógico-curricular no qual se desenvolvem atividades interativas, integradas e integradoras dos conhecimentos e saberes, dos tempos, dos espaços e dos sujeitos envolvidos com a ação educacional. Os macrocampos se constituem, assim, como um eixo a partir do qual se possibilita a integração curricular com vistas ao enfrentamento e à superação da fragmentação e hierarquização dos saberes. Permite, portanto, a articulação entre formas disciplinares e não disciplinares de organização do conhecimento e favorece a diversificação de arranjos curriculares (BRASIL, 2013b, p. 15 - grifo do autor).

Na versão 2013 b, as áreas de conhecimento dos macrocampo passaram por algumas modificações, havendo a substituição do macrocampo "Acompanhamento Pedagógico" pelo macrocampo "Integração Curricular" e a inserção de um novo macrocampo chamado "Línguas Estrangeiras". Houve a junção dos macrocampos relacionados às tecnologias e mídias os quais resultaram no macrocampo "Comunicação, cultura digital e uso de mídias".

Ao todo, continuaram sendo 8 macrocampos, no entanto, houve a modificação quanto ao número de macrocampos que deveriam ser contemplados pelas escolas. Assim, segundo o documento do ProEMI (2013b) a escola deveria contemplar o macrocampo Integração Curricular e pelo menos outros três, os quais ficariam a cargo da escolha das escolas, considerando suas demandas.

Deste modo, ao invés de apenas dois macrocampos obrigatórios, como estava estabelecido no documento orientador de $2011^{13}$, a partir de 2013, na primeira versão do Documento, 4 macrocampos assumem caráter de obrigatoriedade. A escola passa, então, a ter a possibilidade de elaborar seu PRC contemplando todos os 8 macrocampos, apenas alguns macrocampos além dos obrigatórios, ou apenas os 4 macrocampos obrigatórios (Figura 2).

O macrocampo "Integração Curricular" (IC) é apresentado como o espaço para planejar ações educativas que fossem capazes de "produzir maior diálogo e interação entre as áreas do conhecimento/disciplinas, os tempos, os espaços e os sujeitos com vistas a dar maior organicidade ao conjunto de atividades didático-pedagógicos do ensino médio" (BRASIL, 2013b, p. 16).

${ }^{13}$ Acompanhamento Pedagógico e Iniciação Científica. 


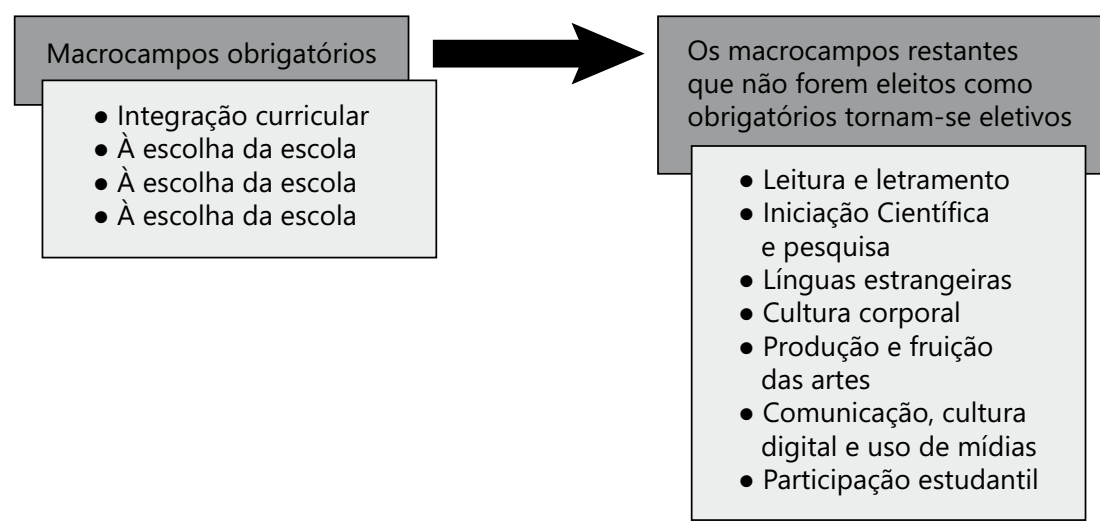

Fonte: Elaborado com base nos dados contidos no documento orientador do Programa Ensino Médio Inovador (BRASIL, 2013b).

Figura 2. Macrocampos ProEMI (BRASI, 2013b).

É interessante destacar que, assim como no documento anterior de 2011, no documento de 2013 foi enfatizada a possibilidade das ações de qualquer macrocampo se apresentarem articuladas a outros macrocampos e/ou articuladas a ações interdisciplinares da escola, no sentido de dar organicidade ao conhecimento escolar e dar forma a um currículo mais integrado (BRASIL, 2011a, 2013b).

Em relação às mudanças ocorridas nos macrocampos chama a atenção a substituição do macrocampo "Acompanhamento Pedagógico" pelo macrocampo "Integração Curricular", o qual teria o papel central no planejamento das ações integradoras nos PRC, uma vez que, segundo o documento orientador, as escolas deveriam passar a organizar seus PRC a partir do macrocampo "Integração Curricular". (BRASIL, 2013b). Esta substituição, porém, não foi mantida, provavelmente devido à compreensão dos formuladores de que o macrocampo "integração curricular" poderia sugerir - ainda que subliminarmente - a necessidade de haver ações pedagógicas integradoras somente neste Macrocampo, o que contraria o que está disposto nas Diretrizes Curriculares Nacionais para o Ensino Médio, base sobre a qual passou a se sustentar o ProEMI desde 2012, quando da homologação dessas diretrizes.

O documento orientador 2013a mantém a centralidade das ações curriculares nos sujeitos do Ensino Médio e orienta que:

A escola deverá organizar o conjunto de ações que compõem o PRC a partir do macrocampo Integração Curricular, conforme necessidades 
e interesses da equipe pedagógica, dos professores, da comunidade escolar, mas, sobretudo, dos adolescentes, jovens e adultos, alunos dessa etapa da educação básica (BRASIL, 2013b, p. 14).

As etapas estratégicas para a elaboração dos $\mathrm{PRC}$, os requisitos para ser um professor articulador e as atribuições deste profissional dentro da escola, as orientações sobre o repasse dos recursos financeiros e os valores a serem repassados, bem como as questões relacionadas ao Acompanhamento e Avaliação do Programa não foram modificados no documento orientador do ProEMI de 2013b.

A partir da análise realizada, é possível constatar que as proposições do ProEMI quanto ao delineamento de novos formatos curriculares no Ensino Médio (conhecimentos, tempos, espaços, sujeitos) foram em sua maioria mantidas. No entanto, merecem destaque as principais mudanças que podem ser vistas na Figura 3.

Conforme, sinalizado anteriormente, o documento orientador de 2013 em sua versão final (BRASIL, 2013a) traz ainda outras alterações. Além da já mencionada mudança do macrocampo "Integração Curricular" que volta a ser chamado de "Acompanhamento Pedagógico", este macrocampo passa a orientar que as

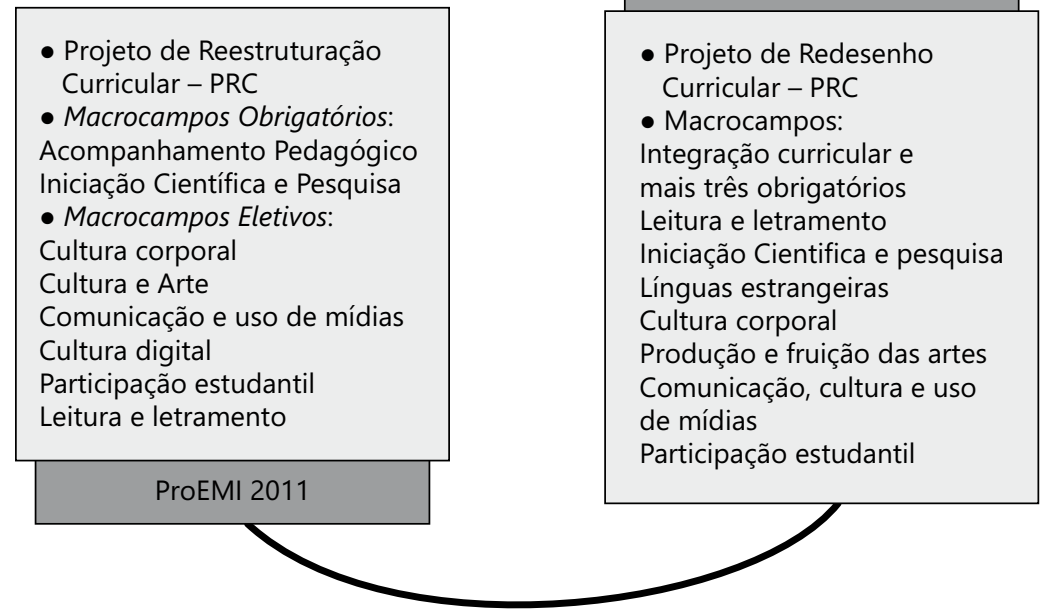

Fonte: Elaborado com base nos dados contidos no documento orientador do Programa Ensino Médio Inovador (BRASIL, 2011a; 2013b).

Figura 3. Síntese das alterações nas proposições doProEMI,Versões 2011 e $2013 a$. 
ações educativas estejam voltadas para o fortalecimento da articulação entre os componentes curriculares:

As atividades propostas, portanto, poderão contemplar um ou mais componentes, tendo em vista o objetivo de aprofundar conhecimentos específicos, seja por necessidade ou interesse, por meio de um planejamento flexível, estabelecendo conteúdos e metodologias diferenciados e contando com maior tempo disponível para professores e estudantes realizarem suas práticas pedagógicas. O macrocampo Acompanhamento Pedagógico poderá contemplar uma ou mais áreas de conhecimento com foco na diversidade de temáticas de interesse geral e de conteúdos (BRASIL, 2013a, p.16).

Na última versão do documento orientador do ProEMI (BRASIL, 2013a), também se observam mudanças nas indicações para implantar o PRC nas escolas. Assim, como condições básicas, foram acrescidos os itens: $\mathrm{b}, \mathrm{c}, \mathrm{f}, \mathrm{e} \mathrm{n}$, os quais passaram a prever:

b) Foco em ações elaboradas a partir das áreas de conhecimento, conforme proposto nas Diretrizes Curriculares Nacionais para o Ensino Médio e que são orientadoras das avaliações do ENEM; c) Ações que articulem os conhecimentos à vida dos estudantes, seus contextos e realidades, a fim de atender suas necessidades e expectativas, considerando as especificidades daqueles que são trabalhadores, tanto urbanos como do campo, de comunidades quilombolas, indígenas, dentre outras; [...] f) Atividades em Línguas Estrangeiras/Adicionais, desenvolvidas em ambientes que utilizem recursos e tecnologias que contribuam para a aprendizagem dos estudantes; [...] n) Todas as mudanças curriculares deverão atender às normas e aos prazos definidos pelos Conselhos Estaduais para que as alterações sejam realizadas (BRASIL, 2013a, p.11-12).

Os itens "b" e "c" estão mais relacionados às concepções e fundamentos que orientam o Programa. Já o item " $\mathrm{f}$ " está em consonância com a criação do novo macrocampo "Línguas Estrangeiras" e o item "n" trata-se de uma orientação mais reguladora das ações do ProEMI.

Outra modificação observada trata do caráter de obrigatoriedade dos macrocampos. Assim, a partir da versão final do documento do ProEMI (BRASIL, 2013a), a escola deveria contemplar três macrocampos obrigatórios (Acompanhamento Pedagógico, Iniciação Científica e Pesquisa e Leitura e Letramento), e mais dois macrocampos de livre escolha com vistas a totalizar ações em no mínimo cinco 
macrocampos (BRASIL, 2013a). A obrigatoriedade dos macrocampos, na versão final, pode ser assim sistematizada como observamos na Figura 4.

A não obrigatoriedade de propor ações em todos os macrocampos, estabelecendo apenas um mínimo, é justificada nos Documentos pela intenção de conferir certa autonomia para a escola, tendo em vista as peculiaridades dos diferentes contextos em que as escolas brasileiras estão inseridas.

Além disso, ao estabelecer uma quantidade mínima de macrocampos a serem contemplados por todas as escolas, o Documento Orientador também induz certa legitimidade no que se refere a uma possível avaliação dos resultados obtidos, tendo em vista a verificação da efetivação do Programa.

Da análise realizada, é possível depreender que as principais alterações ocorridas nos documentos orientadores de 2013 (BRASIL, 2013a,b), são de natureza epistemológica, uma vez que está relacionada às compreensões possíveis em torno da ideia de integração curricular. Os encaminhamentos didático-pedagógicos sofreram poucas alterações. Tais mudanças, portanto, não provocaram impacto na execução da política, uma vez que a ideia de superação de um currículo disciplinarizado, fragmentado e hierarquizado esteve sempre anunciada nas proposições do ProEMI desde sua primeira versão.

Da análise realizada no conjunto dos documentos orientadores disponibilizados entre 2009 e 2013, constata-se mudanças não somente nas áreas de conhecimento abarcadas pelos macrocampos, mas também nas orientações para a organização do currículo e do tempo escolar, bem como nas dimensões que envolvem professores, estudantes e metodologias, conforme é possível observar no Quadro.

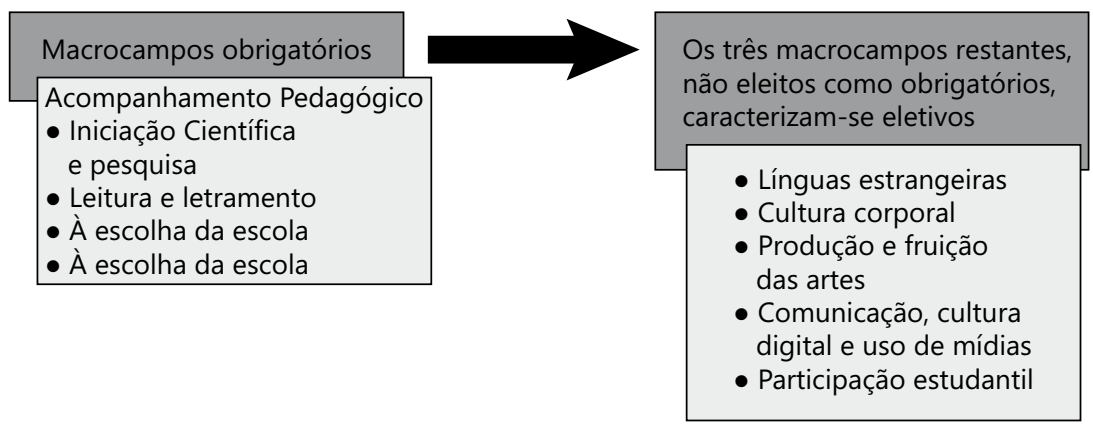

Fonte: Elaborado com base nos dados contidos no documento orientador do Programa Ensino Médio Inovador (BRASIL, 2013a).

Figura 4. Macrocampos obrigatórios e eletivos - ProEMI (2013b). 


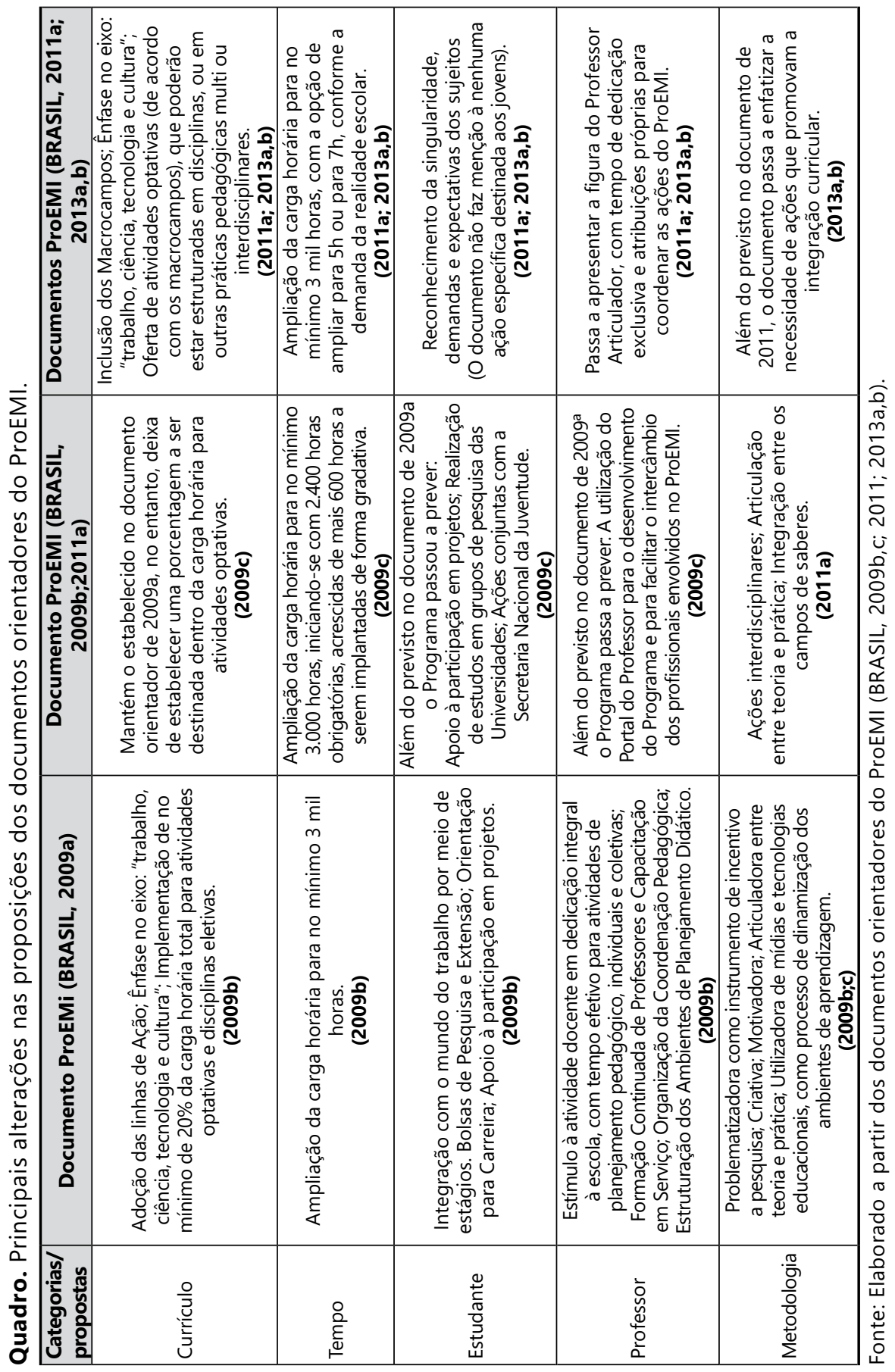


O Quadro permite observar comparativamente as mudanças ocorridas no âmbito dos documentos orientadores do ProEMI. O currículo inicialmente orientado por meio de linhas de ação passa a ser delineado a partir do conceito de macrocampo. A ampliação da jornada escolar foi, ao longo da produção dos documentos orientadores, sendo flexibilizada com vistas a adequar-se à realidade das escolas.

Os estudantes, embora tenham sido centrais em todos os documentos do ProEMI, recebem, a partir de 2011, um tratamento mais abrangente, e não contam com ações específicas como nos documentos de 2009 (Brasil; 2009b;c). O mesmo ocorre com os professores os quais, em 2009 (BRASIL,2009b;c), eram alvo de ações pontuais com vistas ao aperfeiçoamento profissional. A ênfase, no que se refere aos profissionais da educação, a partir de 2011, se desloca para as atribuições referentes à coordenação das atividades do ProEMI na escola. A metodologia e propostas de arranjos curriculares se apresentam de forma plural e diversificada, e passam a defender a perspectiva da integração curricular a partir do ano de 2013 (BRASIL, 2013a;b).

\section{Considerações finais}

As justificativas para criação do Programa Ensino Médio Inovador, conforme atesta o Documento de 2009 e reiterado no Parecer do Conselho Nacional de Educação, seria a de que ele fosse "um incentivo à inovação pedagógica" e uma indução a "um novo paradigma educacional" (BRASIL, 2009a, p. 13). Esses enunciados evidenciam a centralidade conferida à reformulação do currículo da última etapa da Educação Básica. A partir de 2011, tendo sido aprovado o Parecer que daria origem às Diretrizes Curriculares Nacionais para o Ensino Médio - DCNEM [Parecer CNE/CEB n 05/2011 (BRASIL, 2011b) e Resolução $\mathrm{CNE} / \mathrm{CEB} \mathrm{n}^{\circ}$ 02/2012 (BRASIL, 2012)], as ações do Programa tornaram-se com maior evidência uma política de indução a mudanças curriculares com vistas a produzir adesão ao que é postulado por essas Diretrizes.

A análise dos documentos norteadores da implementação do ProEMI permitiu depreender os contextos de influência que incidiram sobre a formulação das propostas do Programa, dentre eles e especialmente, os incorporados nas Diretrizes Curriculares Nacionais para o Ensino Médio, haja vista que essas DCNEM foram objeto de amplo debate, do qual participaram sujeitos e entidades que disputaram os sentidos, a partir dos quais se desenharia a organização pedagógico-curricular da última etapa da educação básica (BRASIL, 2011b).

Vale destacar que não encontramos nos documentos orientadores do ProEMI sequer uma nota explicativa do porquê das mudanças ocorridas em suas proposições no 
período analisado. No entanto, trata-se de um Programa em construção permanente que envolve, além do Ministério da Educação, as Secretarias Estaduais e as escolas, e que, para ser executado, circulam entre estes órgãos vários textos, sejam eles referentes às induções dos documentos orientadores, sejam relativos aos que as escolas e Secretarias produzem em resposta a essas induções. Com base nessa constatação oriunda da pesquisa, é possível depreender que as mudanças nos documentos analisados decorrem justamente desse movimento.

Dito de outro modo, as alterações nos documentos exarados pelo Ministério da Educação ocorreram a partir de informações advindas do próprio processo de implementação, por meio da interlocução entre os vários agentes, sobretudo dos sujeitos nas escolas instados a produzir os textos que compõem os Projetos de reestruturação/redesenho curricular. Esse movimento se explica ao serem interpretados como contextos que demonstram o movimento da política, notadamente as inter-relações entre os contextos de influência, de produção do texto e o contexto da prática, conforme os enunciados da Abordagem do Ciclo de Políticas, referencial teórico-metodológico que orientou as leituras dos documentos coligidos para análise.

A análise sinaliza para a confirmação da hipótese de que as alterações nos documentos são, ao menos em parte, resultantes de um processo de acomodação entre o que é prescrito pelo órgão de governo e as condições de realização do Programa pelas redes de ensino e escolas, ou ainda por possíveis mudanças nos interlocutores ao longo dos cinco anos de existência do Programa. Essa conclusão decorre da amplitude desses interlocutores, seja ao abarcar uma gama bastante diferenciada de sujeitos, de experiências e propostas ao delegar às escolas a elaboração dos projetos escolares/ projetos de reestruturação curricular/ projetos de redesenho curricular, seja ao dialogar com outras ações da política educacional do período. $\mathrm{O}$ alargamento do contexto de influência se verificou, como visto, pela aproximação do ProEMI com outro Programa - o Mais Educação - de onde provavelmente foi retirada a orientação da organização curricular por meio de macrocampos. Para se chegar a estas conclusões, extraídas da análise do conjunto dos documentos normativos do ProEMI, evidenciaram-se relevantes os pressupostos orientadores das leituras, definidos com base na Abordagem do Ciclo de Políticas de S. Ball.

As alterações nos textos de referência do ProEMI resultaram, em síntese, da influência de outros instrumentos e agentes normativos como é o caso das Diretrizes Curriculares Nacionais Gerais da Educação Básica e das Diretrizes Curriculares Nacionais para o Ensino Médio, bem como da amplitude de seus 
interlocutores, que vai do Conselho Nacional de Educação aos sujeitos, que nas escolas interagem com as formulações presentes nos textos. Esse contexto de influência, pelo que indicam as proposições dos documentos analisados, foi marcado, dentre outros aspectos, pelas condições de exequibilidade das induções feitas pelo Programa. Desse modo, cabe ressaltar a pertinência e potencialidade da Abordagem do Ciclo de Políticas para o estudo realizado. Tal abordagem possibilitou atribuir sentido ao movimento identificado nos documentos orientadores e na produção dos textos de referência, bem como permitiu identificar seus interlocutores e os campos de tensão que envolvem a definição dos rumos da última etapa da educação básica. 


\title{
From Text to Context: Programa Ensino Médio Inovador (Innovative High School Program) on the Move
}

\begin{abstract}
This article provides an analysis of an educational policy based on the production of its referential texts. For this aim, the theoretical reflections of $S$. Ball on the Policy Cycle Approach are used. A recent educational policy, the Programa Ensino Médio Inovador (Innovative Middle School Program) - ProEMI, is studied in face of the documents produced in a short period of time as well as the intentions of the Program of bringing about changes in the High Secondary School curricular organization. The analysis points to a hypothesis that the alterations in the documents result, at least in part, from a process of accommodation between what is prescribed by the government agency and the conditions for the implementation of the Program as well as the breadth of the universe of interlocutors involved.
\end{abstract}

Keywords: Educational policy. High secondary school. Programa ensino médio inovador. Policy cycle approach.

\section{Del texto al contexto: el Programa Ensino Médio Innovador (Enseñanza Media Innovadora) en movimiento}

\section{Resumen}

El objetivo de este artículo es analizar una política educativa desde la perspectiva de la producción de sus textos de referencia. A dichos efectos, se utilizará la elaboración teórica de S. Ball sobre el Abordaje del Ciclo de Políticas. Se toma una política educativa reciente, el Programa Ensino Médio Inovador (Programa Enseñanza Media Innovadora) - ProEMI, en virtud del conjunto de documentos producidos en un corto lapso de tiempo, así como del propósito del Programa de fomentar cambios en la organización curricular de los institutos de Escuela Secundaria Superior. El análisis apunta a la hipótesis de que las modificaciones en los documentos resultan, al menos en parte, de un proceso de ajuste entre lo que el órgano de gobierno prescribe y las condiciones de realización del Programa, y también de la amplitud del universo de interlocutores involucrados.

Palabras clave: Política educativa. Escuela secundaria superior. Programa enseñanza media innovadora. Abordaje del ciclo de politicas. 


\section{Referências}

ASCOM SEDUC. Duas mil escolas são contempladas com o Ensino Médio Inovador. Teresina: Governo do Estado do Piú́, 28 ago. 2012. Disponível em: $<$ http://www.piaui.pi.gov.br/noticias/index/id/5686>. Acesso em: 15 abr. 2016.

BALL, S. J. Educational reform: a critical and post-structural approach. Buckingham: Open University Press, 1994.

BALL, S. J.; BOWE, R. Subject departments and the "implementation" of National Curriculum policy: an overview of the issues. Journal of Curriculum Studies, London, v. 24, n. 2, p. 97-115, 1992.

BRASIL. Conselho Nacional de Educação. Parecer CNE/CEB n ${ }^{0}$ 5/2011. Diretrizes Curriculares Nacionais pra o Ensino Médio. Diário Oficial da União, 24 jan. 2012.

. Lei $\mathrm{n}^{\circ}$ 9394, de 20 de dezembro de 1996. Estabelece as diretrizes e bases da Educação Nacional. Diário Oficial da União, 23 dez. 1996.

. Ministério da Educação. Conselho Nacional de Educação. Parecer $\mathrm{n}^{\mathrm{o}} 15$, de $1^{\circ}$ de junho de 1998 . Aprova as Diretrizes Curriculares Nacionais para o ensino médio. Diário Oficial da União, 1 jun. 1998.

. Ministério da Educação. Conselho Nacional de Educação.

Resolução $n^{\circ}$ 2, de 30 de janeiro de 2012. Institui as Diretrizes Curriculares Nacionais para o ensino médio. Diário Oficial da União, 31 jan. 2012.

. Ministério da Educação. Conselho Nacional de Educação. Parecer $\mathrm{n}^{\mathrm{o}} 11$, de 30 de junho de 2009. Apreciação da proposta de experiência curricular inovadora no ensino médio. Diário Oficial da União, 25 ago. 2009d.

BRASIL. Ministério da Educação. Portal MEC. PDDE Interativo. Brasília, DF, 2014. Disponível em: $<$ http://pdeinterativo.mec.gov.br/> Acesso em: 24 jan. 2014.

. Ministério da Educação. Secretaria de Educação Básica.

Diretoria de Concepções e Orientações Curriculares para a Educação Básica. Coordenação Geral de Ensino Médio. Ensino médio inovador. Brasília, DF, 2009b. Disponível em: <http://portal.mec.gov.br/dmdocuments/ensino_ medioinovador.pdf $>$. Acesso: 21 abr. 2016. 
BRASIL. Ministério da Educação. Secretaria de Educação Básica. Diretoria de Concepções e Orientações Curriculares para a Educação Básica. Coordenação Geral de Ensino Médio. Ensino médio inovador: documento orientador. Brasília, DF, 2009c. Disponível em: <http://portal.mec.gov.br/dmdocuments/ documento_orientador.pdf $>$. Acesso: 21 abr. 2016.

. Ministério da Educação. Secretaria de Educação Básica. Diretoria de Concepções e Orientações Curriculares para a Educação Básica. Coordenação Geral de Ensino Médio. Programa ensino médio inovador: documento orientador. Brasília, DF, 2011a. Disponível em: $<$ http://portal.mec.gov.br/index.php?option=com_docman\&task $=$ doc download\&gid=9607\&Itemid $>$. Acesso em: 15 mar. 2016.

. Ministério da Educação. Secretaria de Educação Básica. Diretoria de Concepções e Orientações Curriculares para a Educação Básica. Coordenação Geral de Ensino Médio. Programa ensino médio inovador: documento orientador: versão final. Brasília, DF, 2013a. Disponível em: $<$ http://portal.mec.gov.br/dmdocuments/documento_orientador.pdf $>$. Acesso em: 20 mar. 2016.

- Ministério da Educação. Secretaria de Educação Básica. Diretoria de Concepções e Orientações Curriculares para a Educação Básica. Coordenação Geral de Ensino Médio. Programa ensino médio inovador: documento orientador: versão preliminar. Brasília, DF, 2013b.. Disponível em: <www. seduc.mt.gov.br/download_file.php?id=16000 >. Acesso em: 30 mar. 2016.

. Ministério da Educação. Portaria n ${ }^{\circ}$ 971, de 09 de outubro de 2009. Institui o Programa Ensino Médio Inovador. Brasília, DF: MEC, 2009a.

GARCIA, S. R. O. Ensino médio e educação profissional: breve histórico a partir da LDBEN n. 9394/96. In: AZEVEDO, J. C.; REIS, J. T. Reestruturação do ensino médio: pressupostos teóricos e desafios da prática. São Paulo: Fundação Santillana, 2013.

HOFLING, E. M. Estado e políticas (públicas) sociais.

Cadernos Cedes, Campinas, v. 21, n. 55, p. 30-41, nov. 2001. doi:10.1590/S0101-32622001000300003

KRAWCZYK, N. Políticas para o ensino médio e seu potencial inclusivo. In: $36^{\mathrm{a}}$ Reunião Nacional da ANPEd, 36., 2013. Anais... Goiânia, 29 de setembro a 02 de outubro de 2013. Disponível em: $<$ http://www.36reuniao.anped.org.br/pdfs sessoes_especiais/se_05_norakrawcyk_gt05.pdf >. Acesso em: 21 fev. 2016. 
LOPES, A. C.; MACEDO. Contribuições de Stephen Ball para o estudo de políticas de currículo. In: STEPHEN J. B.; MAINARDES, J. (Org.). Políticas educacionais: questões e dilemas. São Paulo: Cortez, 2011. p. 249-83.

LORENZONI, I. Ensino médio inovador receberá adesão de escolas em fevereiro. Brasília, DF: MEC, 2014. Disponível em: <http://portal.mec.gov.br/ component/content/article?id=20164: ensino-medio-inovador-recebera-adesaode-escolas-em-fevereiro>. Acesso em: 02 fev. 2016.

MAINARDES, J. Abordagem do ciclo de políticas: uma contribuição para a análise de políticas educacionais. Educação \& Sociedade, v. 27, n. 94, p. 47-69, jan./abr. 2006. doi:10.1590/S0101-73302006000100003

MAINARDES, J.; MARCONDES, M. I. Entrevista com Stephen J. Ball: um diálogo sobre justiça social, pesquisa e política educacional. Educação \& Sociedade, Campinas, v. 30, n. 106, p. 303-18, jan./abr. 2009. doi:10.1590/S0101-73302009000100015

MELO, Savana D. G.; DUARTE, Adriana. Políticas para o Ensino médio no Brasil: perspectivas para a universalização. Caderno Cedes, Campinas, v. 31, n. 84, p. 231-51, maio/ago. 2011. doi:10.1590/S0101-32622011000200005

SOUZA, C. Políticas públicas: uma revisão da literatura. Sociologias, Porto Alegre, v. 8, n. 16, p. 20-45, jul./dez. 2006. doi: $10.1590 / \mathrm{S} 1517-45222006000200003$

\section{Informações dos autores}

Monica Ribeiro da Silva: Doutora em Educação, Pontifícia Universidade Católica de São Paulo (PUC-SP). Professora Associada da Universidade Federal do Paraná. Coordenadora do Grupo de Pesquisa Observatório do Ensino Médio. Contato: monicars03@gmail.com

Vanessa Campos de Lara Jakimiu: Doutoranda em Educação na linha de Políticas Educacionais, UFPR. Professora no Curso de Pedagogia da Universidade Estadual do Paraná - Campus União da Vitória. Membro do Grupo de Pesquisa Observatório do Ensino Médio. Contato: vanessajakimiu.emi@gmail.com 